\title{
Approaches to Modernizing the Architectural and Planning Structure of Maternity Institutions in the Context of a Pandemic and a New Social Distance
}

\author{
Alexandra Chashchina ${ }^{1}$, Andra Ulme ${ }^{2^{*}}$, Anatoly Skopintsev ${ }^{3}$ \\ 1,3 The Academy of Architecture and Arts of Southern Federal University, Rostov-on-Don, Russia \\ 2 Institute of Design Technologies, Faculty of Materials Science and Applied Chemistry, \\ Riga Technical University, Riga, Latvia
}

Received 2021-01-12, accepted 2021-07-01

\section{Keywords}

Adaptive therapeutic environment, maternity facility, modernization, social distance, space boundaries.

\begin{abstract}
The article discusses individual approaches to the formation of the architectural and spatial environment of maternity hospitals and perinatal centres contributing to social distancing. A 'functional-spatial' approach is proposed, in which the boundaries of spaces in the most active functional areas of the maternity hospital are changed: entrance area, reception of women in labour, area for relatives and visitors of the hospital, delivery of newborns, consultations in the polyclinic department of the maternity hospital. As a planning technique for distancing is proposed the formation of a system of space 'soft borders' using flexible, inclined, semicylindrical and 'flowing' translucent partitions. The second, 'environmental approach', is based on changing the scheme of communication and environmental situations in the internal environment of the maternity hospital due to the thoughtful arrangement of furniture and interior equipment, as well as due to light, colour and graphic navigation. Such a reorganization of the architectural and spatial structure of the maternity hospitals, based on the requirements of social distancing, preserves the value characteristics of the therapeutic environment.
\end{abstract}

\section{Introduction}

The circumstances that the world is facing today in the form of a new global threat to human health - a pandemic, radically change the approaches to the formation of the architectural space of medical institutions which have a large flow of visitors. This situation is most acute in the field of medical institutions for women during childbirth. New rules of social distancing change habitual behavioural situations, rules of visiting and serving patients. Uncomfortable stress situations arise in institutions set up in old buildings with a lack of space. This affects the emotional state of women and partly poses a threat to the therapeutic environment of institutions. Therefore, it becomes urgent to search for methods of modernizing the planning of architectural, spatial and infrastructure systems taking into consideration the new way of life in which architecture will respond to the prevailing circumstances due to the 'flexibility' of internal spaces.

The object of this research is maternity hospitals. This term is adopted in Russia, as well as in some European countries: England, France. A maternity hospital (abbreviated in Russian as роддом) is a medical institution that provides qualified medical care for women during pregnancy, during childbirth and in the postpartum period, as well as medical care for the new-borns.

For women in Germany, there are three options of obstetrics: a clinic, maternity homes (for a relaxing 
atmosphere) or a midwife's home visit. There are no maternity hospitals in the United States in the Russian sense. There are hospitals that have special departments for childbirth. In general, a maternity hospital refers to a medical facility in which women carry out 'natural childbirth' or aggravated childbirth with surgical intervention. Institutions in which a woman is during childbirth and during pregnancy receive a range of additional services: antenatal and postnatal consultations, examination, preparation for childbirth and postnatal medical care, as a rule, are called clinics, medical centres. In Russia these are called perinatal centres. The conditions of the pandemic partly change the usual environment of maternity hospitals and require to search for new methods of their spatial organization.

The subject of the research is the architectural and spatial solutions of individual functional areas of these institutions in the context of a pandemic and social distancing. At the same time, it is taken into consideration that one of the important qualities of architectural and spatial environment of maternity hospitals is its therapeutic and relaxing effect on women in labour, which contributes to their positive emotional state.

The purpose of this study is to develop effective methods of architectural and spatial transformation and transformation of the internal and external environment of maternity hospitals, taking into consideration the provision of social distancing and the maximum possible preservation of the qualities of therapeutic environment.

The tasks that are solved to achieve this goal include:

- identification of the main qualities of therapeutic environment in relation to maternity hospitals, taking into consideration the positive experience of different countries;

- determination of the most relevant functional zones (spaces) of maternity hospitals with a large flow of visitors in need of social distancing and architectural and spatial transformation;

- the choice of effective methods of possible spatial transformation of these functional zones, taking into account the rules of behaviour, the technology of staff work and the characteristics of maintaining the therapeutic qualities of the architectural environment.

\section{Methods and Approaches}

The concept of therapeutic environment is a promising direction for the modernization and improvement of the architectural and spatial structure of medical institutions, including maternity hospitals. An analysis of the best practices in the functioning of maternity hospitals shows that the main factors in creating such a therapeutic environment that have a positive therapeutic effect on patients are: a) use of modern equipment and treatment technologies; b) polite, caring and professional medical staff; c) architectural and artistic qualities of the interior and exterior environment of a medical institution (for example, Pilates and fascia, Marie-José Blom, in Fascia: The Tensional Network of the Human Body, 2012).

Maternity hospitals and clinics in many foreign countries are characterized by significant success in the formation of such a positive therapeutic environment: much attention is paid to this in the network of maternity hospitals in Australia [1] and in a number of European countries [2], [3], [4]. In obstetrics institutions in Edinburgh, Great Britain, an emphasis is placed on the spiritual state of women in labour, purposefully shaping the interior as a continuation of spiritual practices that improve the mind, body, spirit, and feelings of women [5], [6]. At the Ronald Reagan Medical Center, the emphasis is placed on the use of light 'positive' tones of colour and contrasts in the interiors, green recreation, magnificent views of the bay opening from the birth wards, which forms a positive emotional background for the patients.

In Russian practice, maternity hospitals can be conditionally divided into two types: conservative and progressive. The conservative hospitals have inherited working methods, equipment and buildings from the USSR, while the progressive ones (more often paid for) try to work according to European principles with modern equipment and an adaptive architectural environment, which is typical for large cities. Most provincial towns and settlements are characterized by low quality of interior and external appearance of maternity hospitals; there is a lack of green recreation, spaces for rest, relaxation, which evokes a negative reaction from patients [7]. For this purpose, separate areas of improvement and modernization of such facilities are being developed [8]. At the same time, no relevant research has yet been conducted on the new rules of social distancing affecting the already established therapeutic environment in the maternity hospitals. Analysis and comparison of the functional planning structure of maternity hospitals in a number of foreign countries and in Russia made it possible to identify characteristic functional zones and premises, the 'thought out' interior environment of which can have a therapeutic and positive emotional and psychological effect on women in labour. These include: a) the entrance area of the maternity hospital (clinic); b) the area for reception and registration of women in labour (admission department); c) a meeting area for relatives with women in labour and hospital visitors (for transmissions and communication); d) zone of discharge of women in labour and delivery of newborns; e) zone of consultation and medical care in the polyclinic department.

It is proposed to have two approaches as the basis for a possible modernization of the planning structure of the maternity hospitals, contributing to social distancing: a) functional-spatial and b) environmental approach. For illustration, typical planning schemes of the maternity 
hospitals in Krasnodar and in Rostov-on-Don (Russia) were taken to demonstrate the principal architectural and spatial solutions. One of them is the Regional Perinatal Centre that was opened on 11 April 2011.

The functional-spatial approach allows to change and optimize the boundaries of spaces within individual functional areas using buffer and empty areas. Several methods can be considered within this approach to modernize individual functional areas of the maternity hospitals.

\section{Methods of entrance area transformation}

In a number of institutions, this room is combined with a polyclinic, a department for receiving women in labour, or exists as an independent zone. In this case it includes space for hospital visitors, pharmacy, cloakroom, reception, restrooms, security post, and cafeteria. Depending on the area and set of functions, advantage should be taken of one of the possibilities of space transformation due to conditional 'soft' borders, which are a light-transparent fabric structure stretched over the frame in smooth and flexible forms (see Fig. 1).

The outline of the partition in plan and silhouette creates comfortable visual boundaries for patients, forming their positive psycho-emotional state. The collapsible design of the partitions makes it possible to quickly respond to the flow of visitors through a system of modular fasteners in the floor (Fig. 1). This makes it possible to separate the flow of incoming and outgoing visitors, as well as to zone the reception area with soft and smooth lines, since this place usually has a large crowd of people. There should be a separate reception window for those who just entered, as well as 1-2 windows for those who have already been to the reception and want to make an appointment again. But the key task is to ensure that these flows are separated and cannot cross.

The scenario of movement of visitors is a starting point where it must be noted that spatial boundaries are defined and the condition of 'physical volume' of women with regard to their belly without causing them discomfort and tightness conditions is taken into consideration.
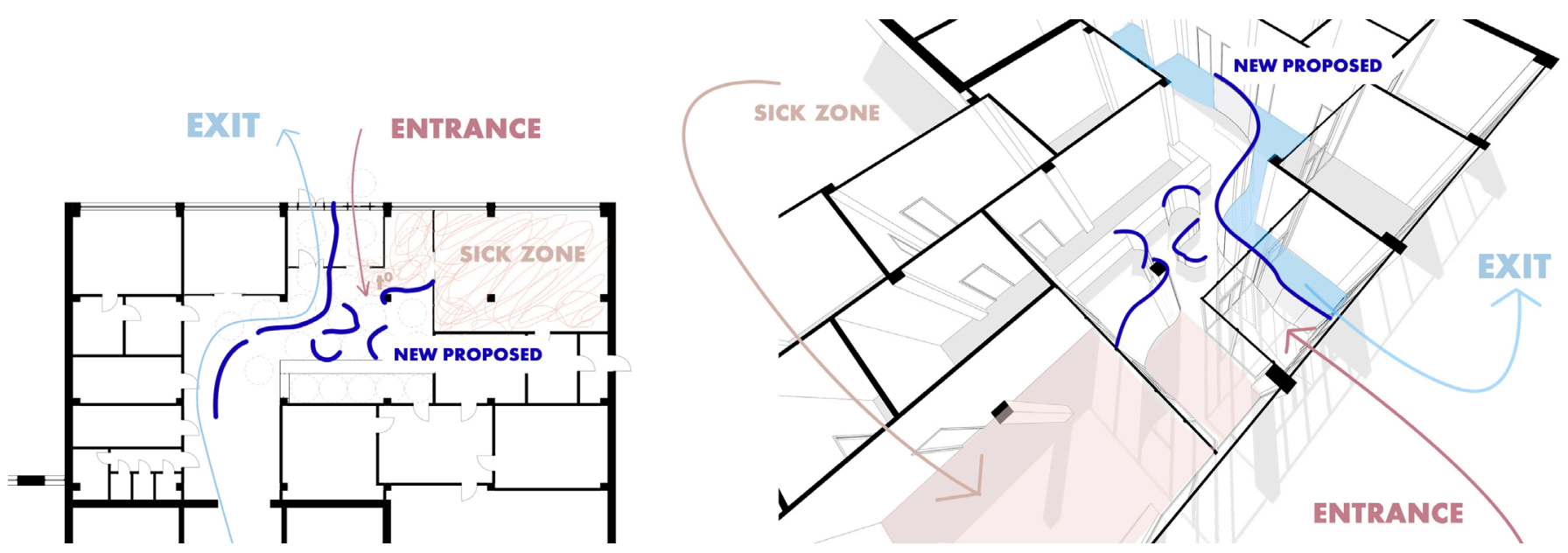

Fig. 1. Example of entrance zone modernization using 'soft' borders-partitions [authors].
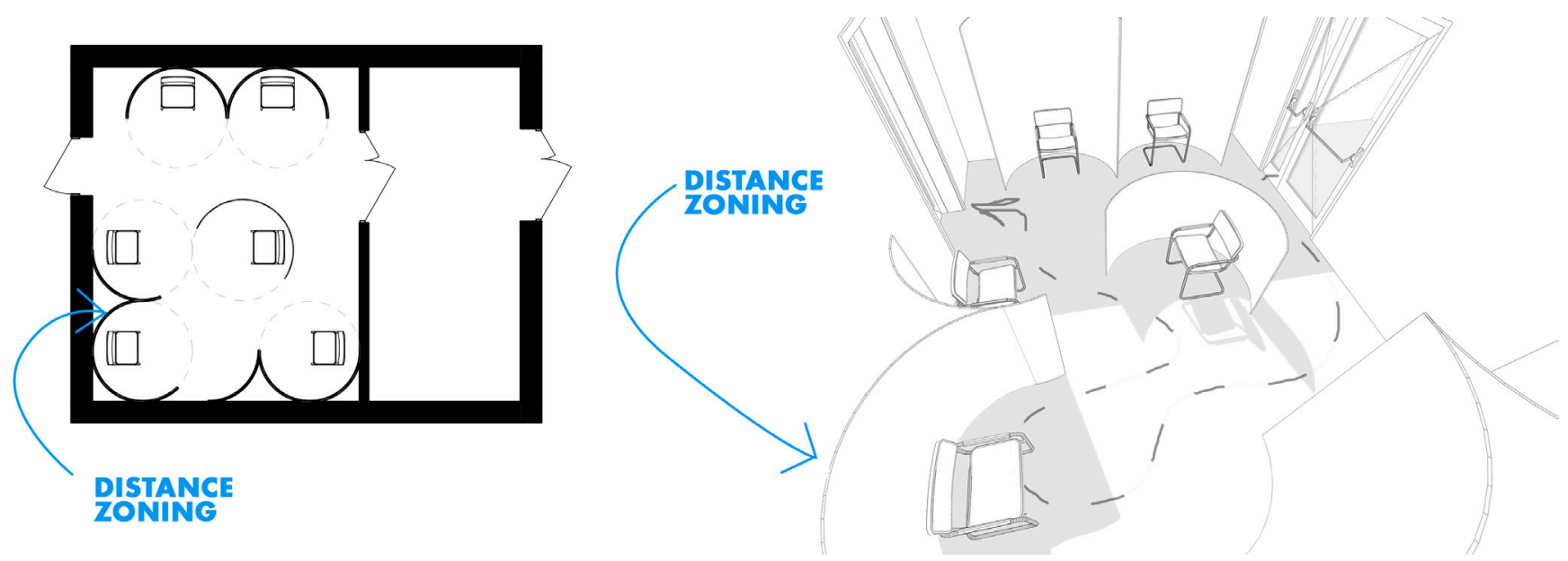

Fig. 2. Modular transformation of the reception room space with autonomous half-cylindrical partitions [authors]. 
Modernization of the reception

area for women in labour

It is a distribution node that includes a vestibule, waiting area, reception rooms, observation rooms, bathrooms, shower and staircase and elevator block. It is most difficult to keep a distance in the waiting area, since there are several women in labour with relatives who could have arrived by ambulance or independently, and emergency hospitalization may be necessary. Often, visitors are in a panic and keeping the distance goes by the wayside. To simplify the process and insure the distance is kept, the same system of translucent partitions-borders but in a different configuration must be introduced. It is worth starting from the radial half-cylinders, which will create their own autonomous safe zone for everyone. Depending on the room area, these partitions can be transformed, shifted or moved apart, forming new borders (Fig. 2). The system of autonomous individual spaces with semi-cylindrical borders in the plan creates a relaxing environment for women in labour and visitors with the necessary social distance.

Conversion methods of the area for relatives and hospital visitors

The area for relatives and hospital visitors is one of those places where women exchange their emotions. To date, due to the epidemiological situation, many institutions have a restricted access to it. This problem can be solved by creating translucent structures, placing them in a 'buffer space', which to date has proved ineffective due to the extreme measures taken. To maintain a safe distance, it is necessary to place the structure at an angle, due to which it will not be possible to get closer than 1.5$2.0 \mathrm{~m}$ (Fig. 3).

Inclined transparent partitions also 'help' paths of movement inside the maternity facility, regulate the intensity and 'smoothness' of movement of people with the maximum use of each room capacity (Fig. 4).
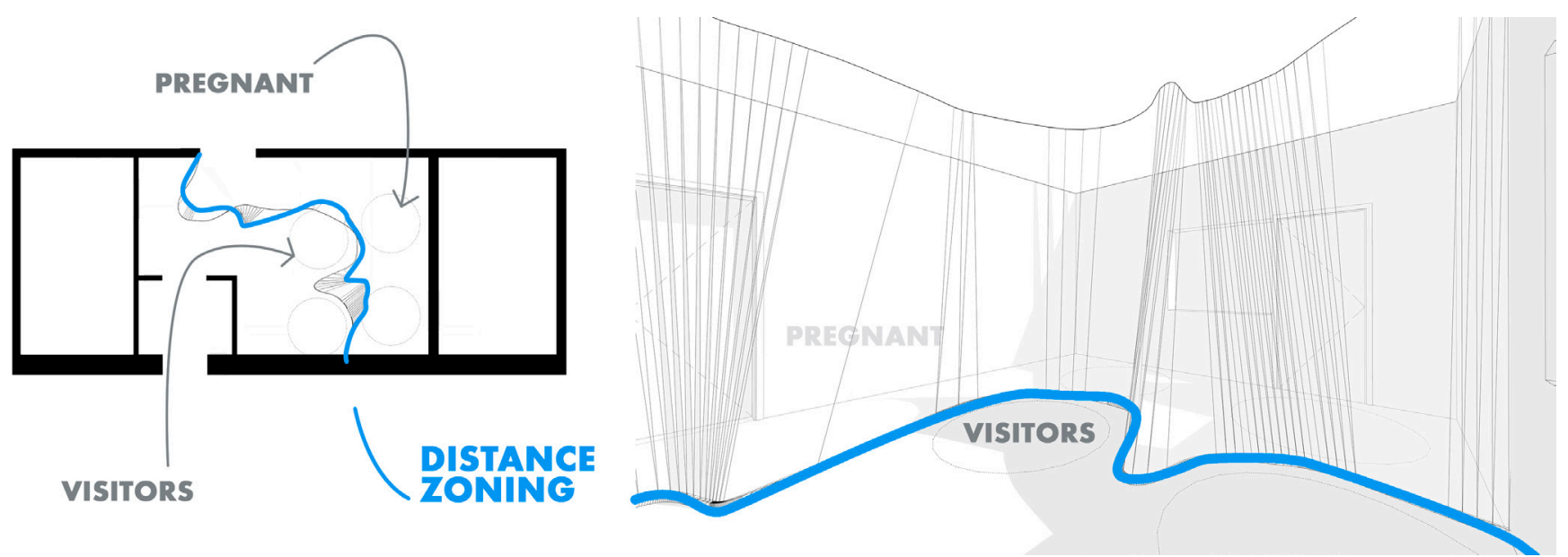

Fig. 3. Techniques for creating 'symbolic' safe borders in the family visiting area [authors].

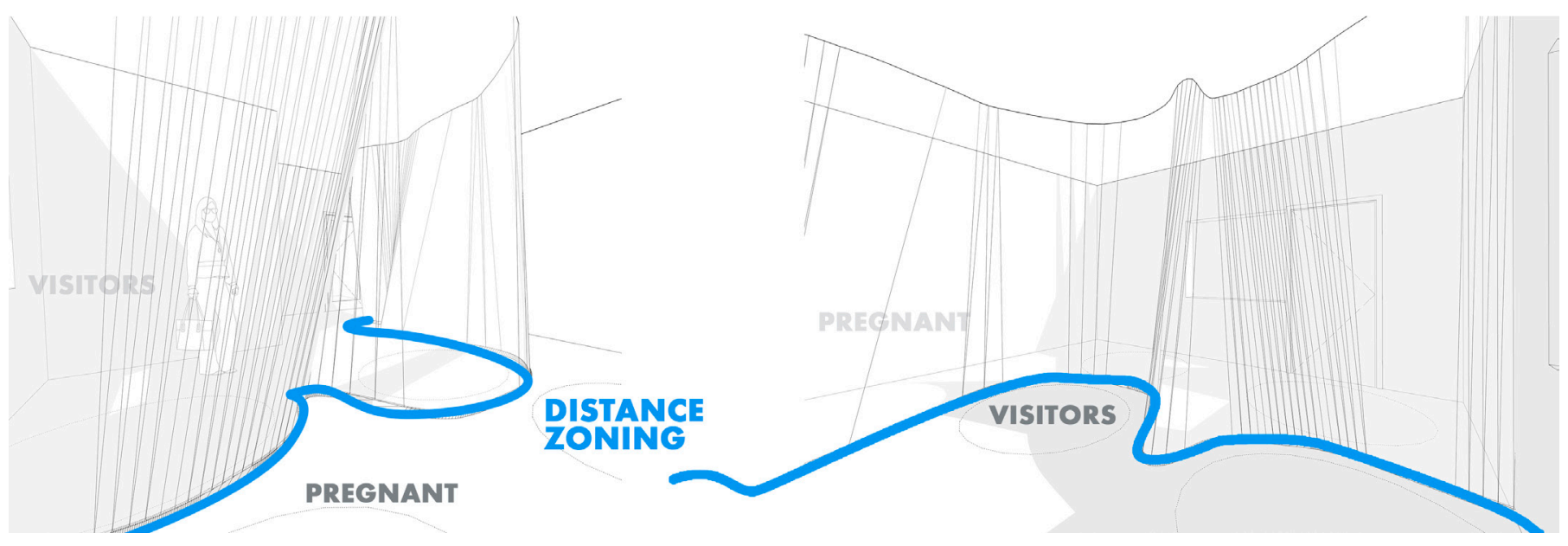

Fig. 4. Example of using inclined translucent structures to maintain social distance and form a new design of the communication zone of patients with visitors [authors]. 
Methods and techniques for modernizing the space of discharge zone (delivery of newborns)

At present, this space of the solemn meeting of mother and child can be organized as a conditional 'flow' from the inside out (Fig. 5). This creates an opportunity not to let a large number of people into the room, but when the mother and child leave, form the symbolic 'spatial path' in which relatives would meet at certain distances maintaining the necessary social distance.

The linear environment of such a translucent communication can be supplemented with a festive functional-spatial scenario using lighting and play equipment, forming a new scenography of the architectural space of the newborn delivery department (Fig. 6).

A spectacular technique can be a composition of festive balloons over the discharge area, flexibly reacting to the situation. Using balls in the form of plastic lamps with a diameter of 1.0 metre, a light-dynamic scenario can be created in which the balls will change the light when a boy or girl is discharged and then switch to warm light mode.
Ways of possible transformation of consultation area in a polyclinic department

The department of consulting reception, which is part of the maternity hospital structure, can be combined with a common lobby with a hospital or be a separate planning block. To date, it is difficult to control the maintenance of social distancing in such zones, since with the restriction of landing places, the remaining group of people will stand at the offices and wait for their turn. It is proposed to solve this problem in several ways:

a) by functionally separating the incoming and outgoing flows by a system of previously described flexible partitions;

b) maximum use of the reserve area in the registration zone, taking into consideration its zoning by transparent walls with semi-cylindrical forms, and the creation of autonomous micro-spaces for waiting for the reception (Fig. 7);

c) colour-functional layout and visual spots can be used to designate areas where people should be placed in a queue.
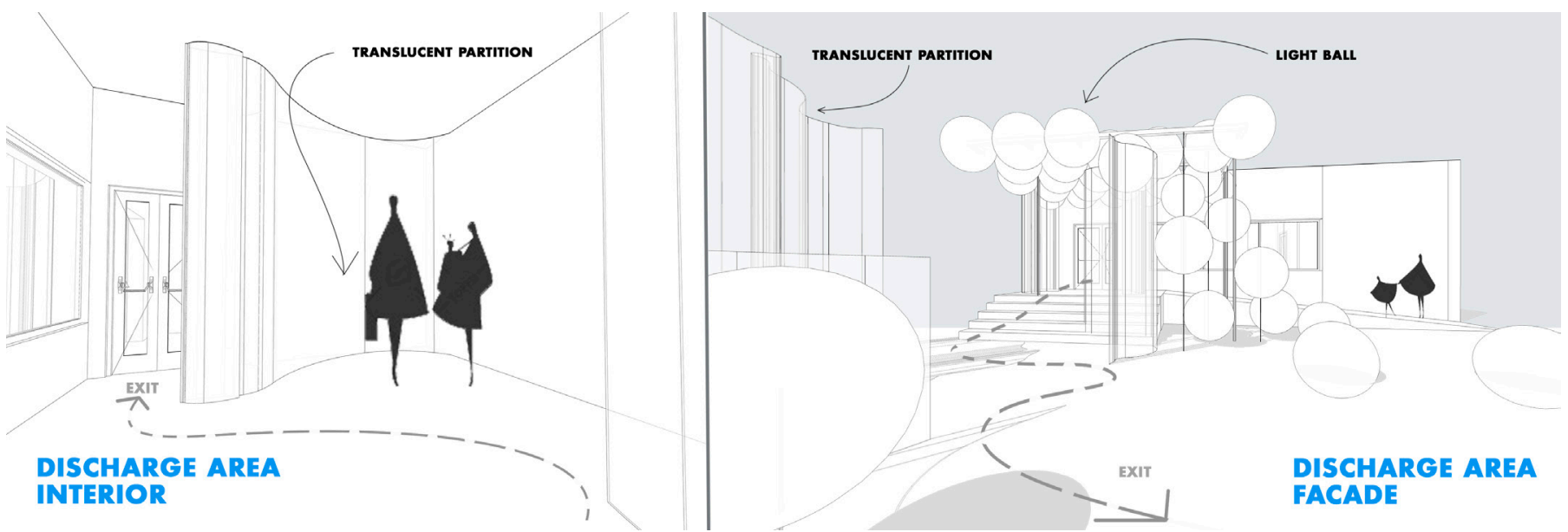

Fig. 5. Method of organizing the space for 'flowing from inside out' in the area of discharge and delivery of newborns [authors].
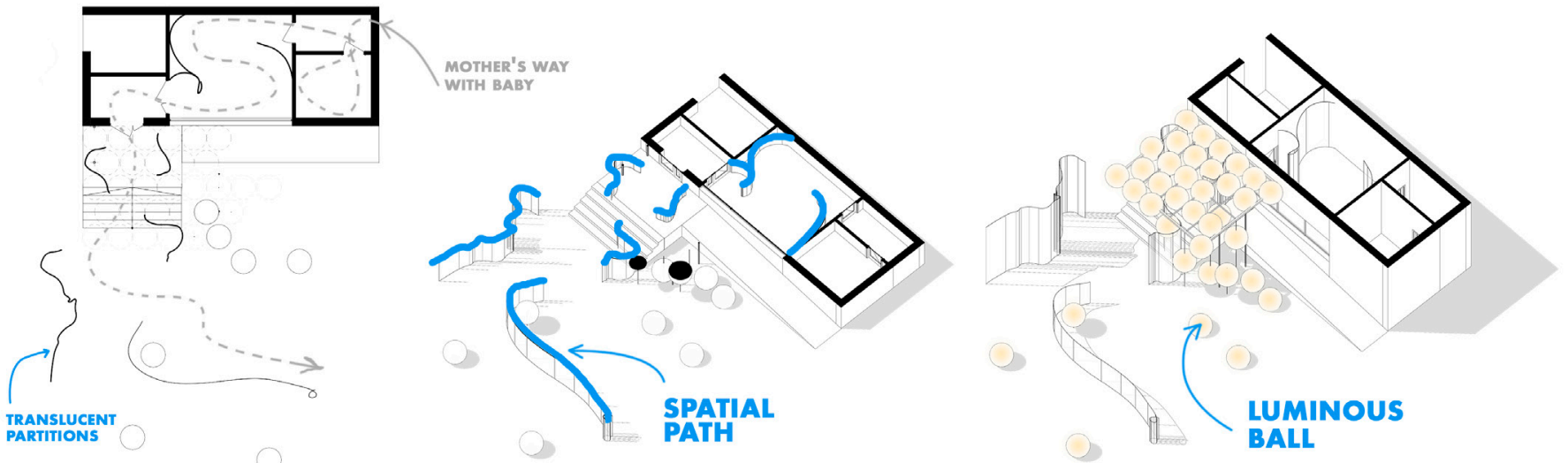

Fig. 6. Method of organizing the zone of discharge of newborns maintaining the social distancing conditions [authors]. 
In the case of little space in the reception and waiting areas, it is suggested to use another technique instead of partition walls - visual border with light. This distinction is more like a 'game' of light spots, in which a kind of 'laser maze' indicate the areas for sitting or standing. In these areas, there may be a stationary chair / arm chair and a place for things that women bring with them when coming to the hospital (Fig. 7).

This study suggests to use the functional-spatial approach along with environmental approach in order to create a comfortable therapeutic environment in maternity hospitals in the context of a pandemic. The environmental approach is based on transformation of the communication scheme and communication situations in connection with the current pandemic situation.

The following methods of transformation of recreational and communication zones in the interior of maternity hospitals in conditions of distancing are proposed:
1) formation of communication system and environment boundaries by placing furniture;

2) regulation of environmental situations and movement using graphical navigation.

In a maternity hospital, architectural environment and graphical navigation should assist in shaping the paths of movement and maintaining the distance. Options for implementing such a system are the main points of distribution that are responsible for distancing; a path is a thin solid line on the floor or in the lighting system transparent structures to be built (Fig. 8).

Maintaining a distance on the path of movement should be done with accent spots, not zones. It is possible to disperse geometric shapes at a certain distance and thus create a 'field of motion'. Also, working with large-scale relationships, you can distribute figures of different diameters by creating a new system of visual communication in the environment with them.
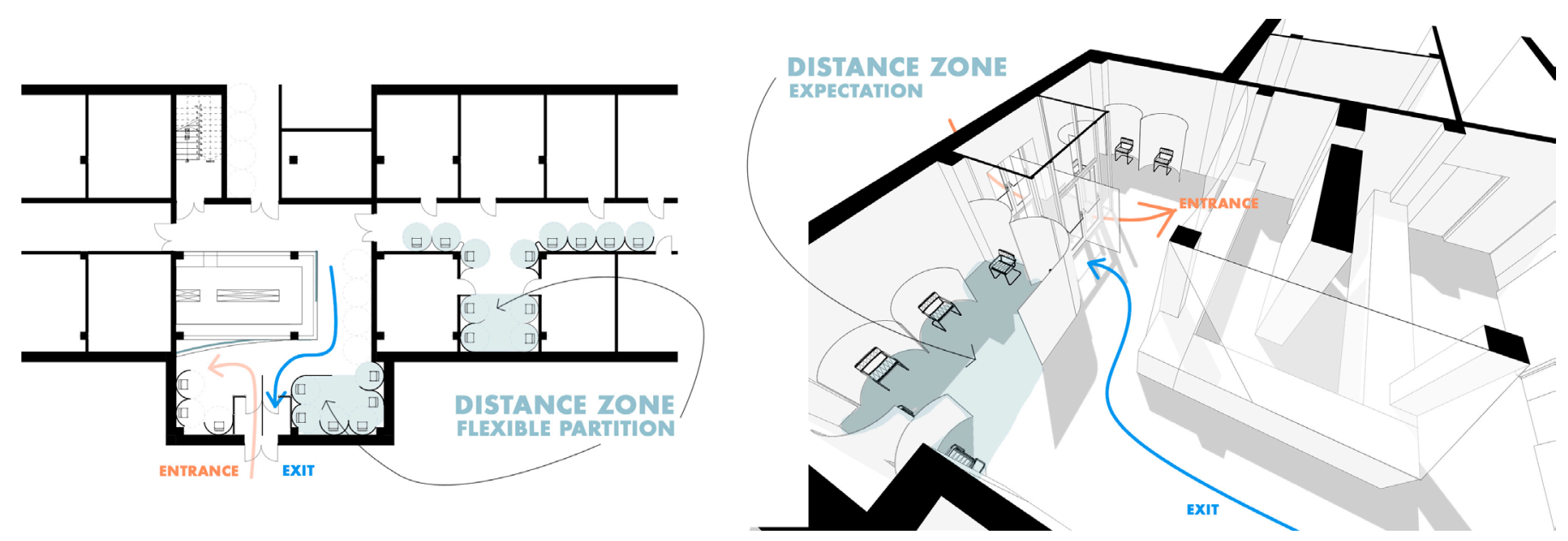

Fig. 7. Method of functional zoning of spaces of the reception and halls with semi-cylindrical partitions for distancing conditions [authors].
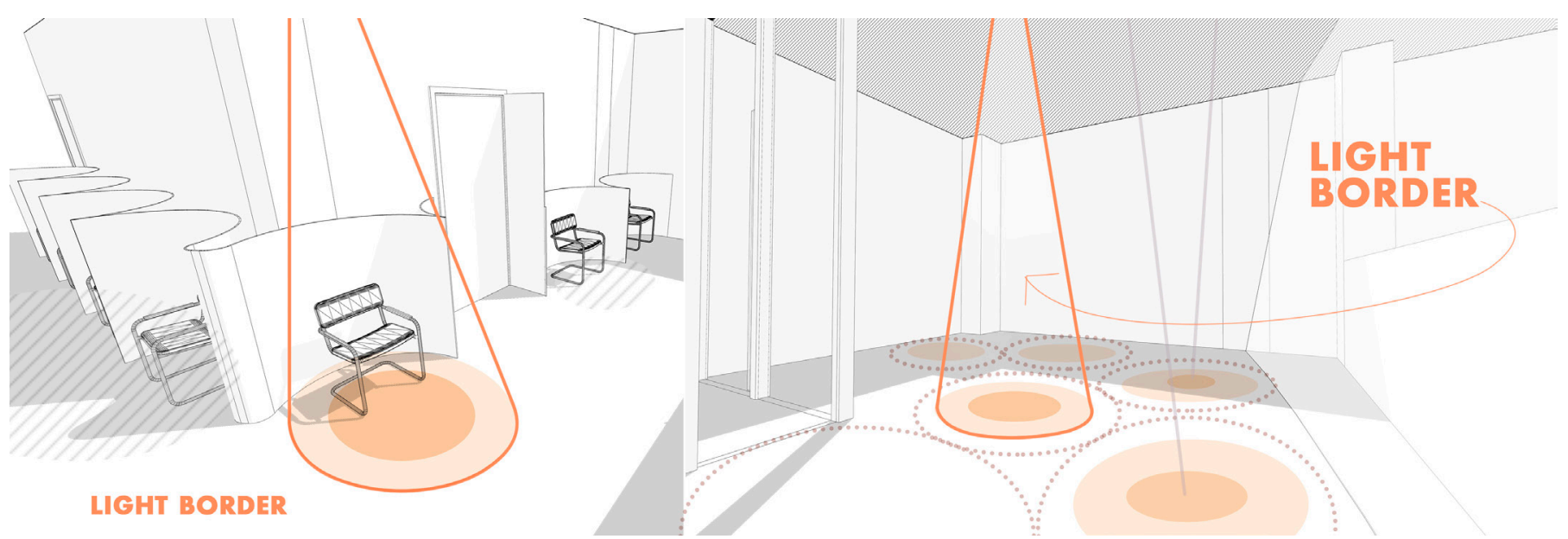

Fig. 8. Social distancing method in the polyclinic department of maternity hospital using light spots as interactive borders [authors]. 


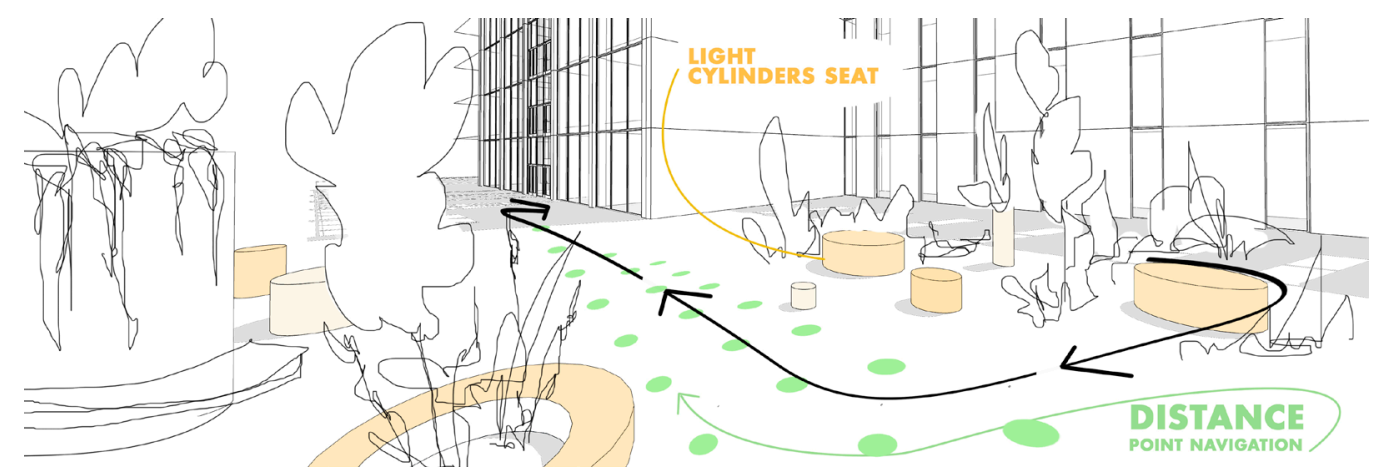

Fig. 9. Method of forming safe distances and movement routes using graphical navigation [authors].

\section{Discussion and Results}

This study proposes a number of fundamental approaches and methods aimed at improving the architectural and spatial solutions of maternity hospitals taking into consideration their adaptation to the conditions of the pandemic.

An analysis of scientific works on this issue shows the importance of preserving a special therapeutic environment of these institutions as an additional therapeutic factor that affects the emotional state of patients [9], [10], [11]. Using examples of advanced experience, the author considers the characteristic qualities of this environment associated with the formation of large-scale and comfortable spaces and care for the psycho-emotional state of women in labour [2], [3], [4], [5], [6], [7].

At the same time, the issue of maintaining such a therapeutic environment in maternity hospitals in the face of a pandemic and social distancing have not yet been studied in detail. The methods proposed in this study partly contribute to achieving this goal.

Indirectly, the prospects of the proposed methods are indicated in the studies of the problems of planning preparedness for pandemic influenza of large maternity hospitals in the United States [12] as well as in studying the problems of designing future hospitals and the peculiarities of their functioning in the context of a pandemic and quarantine [13], [14].

Specific methods of transformation and transformation of space with the help of translucent 'soft' partitions and means of light and graphic communication have found their confirmation in the advanced design experience. Such experiments include the use of 'colourspotted' design in New York City parks to highlight safe distances and spacing in public spaces as well as symbolic white circles on the grass that promote social distancing [15], [16].

\section{Conclusions}

1. Analysis of the positive experience of different countries made it possible to establish that the main qualities of the healing environment of maternity hospitals are technological equipment and caring medical personnel, as well as the architectural and artistic qualities of the interior, including proportionate and visually comfortable spaces, 'green' recreation areas ensuring relaxation contributing to the spiritual, physical and psycho-emotional recovery of patients.

2. Based on the generalization of planning solutions, the most relevant functional and architectural-spatial zones of maternity hospitals have been identified, which form a therapeutic environment and have a large flow of visitors in need of social distancing.

3. A number of fundamental approaches to adapting the therapeutic environment of the maternity hospitals to the conditions of social distancing are proposed: architectural-spatial approach - in which the boundaries of the spaces of individual functional zones and premises change; environmental approach in which the communication scheme changes, the environment becomes autonomous, there is a transition from the public to the individual environment.

4. Effective methods of spatial modernization of the functional zones of maternity hospitals are proposed, taking into account the requirements of social distancing and maintaining the therapeutic environment: a) the most effective method is construction of translucent, flexible boundaries-partitions of various configurations; b) for communicative spaces, waiting areas of the polyclinic department, recreation and recreation areas, the most effective methods are light-coloured, graphic navigation, modelling the environment by placing equipment, furniture, container gardening; c) for ceremonial spaces (zones of unloading and delivery of newborns), the method of 'scenography of space' is optimal using visual communication tools, infographics, as well as 'smooth' boundaries-partitions. 


\section{REFERENCES}

1. Fahy, K. M., Parratt, J. A. Birth Territory: a theory for midwifery practice. Women and birth. Journal of the Australian College of Midwives, vol. 19, no. 2, 2006, pp. 45-50. https://doi.org/10.1016/j.wombi.2006.05.001

2. Purves, G. Primary Care Centres: A Guide to Health Care Design. Second Edition. London: Routledge, 2009. 216 p. https://doi.org/10.4324/9780080940663

3. Fahy, K. M., Foureur, M., Hastie, C. Birth Territory and Midwifery Guardianship: Theory for Practice, Education and Research, 1st Edition. Books for Midwives, 2008. 198 p.

4. Pilkington, H., Blondel, B., Papiemik, E., Cuttini, M., Charreire, H., Maier, R. F., Petrou, S., Combier, E., Kuenzel, W., Breart, G., Zeitlin, J., MOSAIC group. Distribution of maternity units and spatial access to specialized care for women delivering before 32 weeks of gestation in Europe. Health \& Place, vol. 16, no. 3, 2010, pp. 531-538. https://doi. org/10.1016/j.healthplace.2009.12.011

5. Parratt, J. A. Territories of the self and spiritual practices during childbirth. In Birth territory and midwifery guardianship: theory for practice, education and research. Elsevier Health Sciences, 2008. pp. 39-54.

6. Frank, K. A., Lepori, R. B. Architecture from the inside out: From the body, the senses, the site, and the community, 2nd edition. Chichester, UK: Academy Press, 2007. 200 p.

7. Chashchina, A., Skopintsev, A. Analysis of the Current State of the Architectural Environment of Maternity Hospitals and Perinatal Centers (On the Example of Cities of the South of Russia). Bulletin of Belgorod State Technological University named after. V. G. Shukhov, vol. 5, no. 4, 2020, pp. 74-83. https://doi.org/10.34031/2071-7318-2020-5-4-74-83

8. Chebereva, $\mathbf{0}$. N. Architectural modernization Principles of Medical Somatic Hospitals complexes (on the example of Nizhny Novgorod city hospitals): PhD thesis of Architecture. NN., 2009. 210 p. [online 15.08.2020]. https://www. dissercat.com/content/printsipy-arkhitekturnoimodernizatsii-kompleksov-meditsinskikh-somaticheskikhstatsionarov-

9. Chebereva, 0. N. Medical Hospital Architecture as a Medical Architecture. Collection of works of postgraduates and undergraduates. Architecture. Geoecology. Economy. Nizhny Novgorod State University of Architecture and Civil Engineering. 2003. pp. 38-42.

10. Health Building Note 09-02: Maternity Care Facilities. Department of Health. London, 2013. 82 p. [online]. Gov.uk [cited 01.12.2020]. https://assets.publishing.service.gov. uk/government/uploads/system/uploads/attachment_ data/file/147876/HBN_09-02_Final.pdf

11. Purves, G. Healthy Living Centers a guide to primary health care design. $1^{\text {st }}$ ed. Architectural Press, 2002. 241 p.

12. Beigi, R. H., Davis, G., Hodges, J., Akers, A. Preparedness planning for pandemic influenza among large US maternity hospitals. Emerging Health Threats Journal, 2009, vol. 2, e2. https://doi.org/10.3134/ehtj.09.002

13. Thoughts on a Pandemic: Designing Hospitals for the Future [online]. RMJM [cited 25.08.2020] https://www.rmjm.com/ thoughts-pandemic-design-hospitals-future/
14. Hyperfunctional Logics for the Quarantined City [online]. Quarantinology [cited 20.10.2020] http://quarantinology. com/

15. Paula Scher High Line covers in green dots to encourage social distancing [online], Dezeen [cited 15.08.2020] https:// www.dezeen.com/2020/07/21/paula-scher-graphics-highline-social-distancing/

16. Crop circles: a social distancing experience at Domino Park in New York [online]. Posta-Magazine [cited 10.11.2020] https://posta-magazine.ru/article/domino-park-circlessocial-distancing/

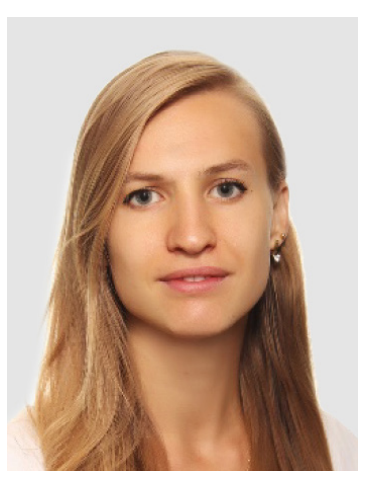

Alexandra Chashchina received her degree of Master of Architecture from the Academy of Architecture and Arts of the Southern Federal University, Russia, in 2016 and is currently a PhD student of the Architectural Academy of Architecture and Arts of the Southern Federal University.

She works as an architect. Her research interests are modern problems of architecture, modernization of public spaces.

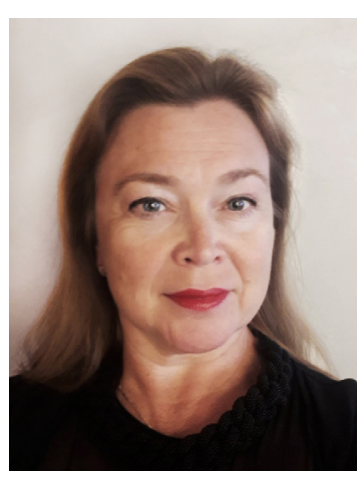

Andra Ulme, Dr. arch., is an Associated Professor with the Institute of Design Technologies of Faculty of Materials Science and Applied Chemistry of RTU. Since 2004, she has been an Assistant Professor, and from 2015 an Associated Professor with RTU. She has been an interior architect and designer, specializing in public and private interiors, specializing in hotel interior design, has completed more than 25 projects in suburbs over the last ten years, mostly in luxury style. She is the author of more than 45 publications about spatial design, architecture, urban planning, history of architecture, accessibility of environment, Universal Design, and educational problems published in Latvia, Estonia, Lithuania, Croatia, Poland, Portugal, Italy, Greece, and Russia. Since 2017, she has been an international expert in architecture, design and art. Her research interests are architecture, contemporary problems of architectural and design education, VR, exploration of unutilized hidden resources and research of utilization possibility of these resources to promote the development of national economy of Latvia. 


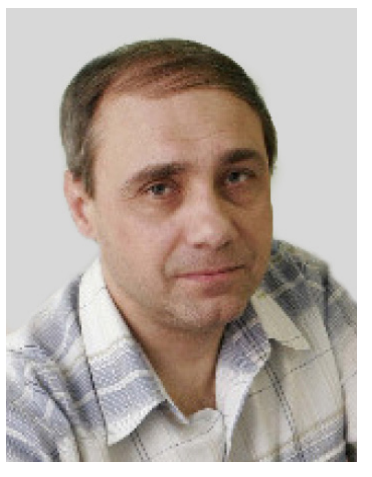

Anatoly Skopintsev holds a $\mathrm{PhD}$ in Architecture, He is a Professor with the Academy of Architecture and Arts of the Southern Federal University, Russia. Since 2000, he has been an Associate Professor, and since 2013, a Professor with the Department of Architectural and Environmental Design of the AAI SFedU. He is an Honorary Worker of Higher Professional Education; a member of the Union of Architects of the Russian Federation; author of a number of projects for residential and public buildings. He has published over 27 scientific articles on architecture and environmental design, including 2 publications in journals indexed in the Scopus database.

\section{Contact Data}

\section{Alexandra Chashchina}

Academy of Architecture and Arts of the Southern Federal University, Rostov-on-Don, 39 Budennovsky Str., 344002 Russia

Phone: + 79895280057

E-mail: leksa-07@yandex.ru

\section{Andra Ulme}

Institute of Design Technologies, Riga Technical University, Kipsalas Str. 6, Room 432, Riga, LV-1048, Latvia

Phone: + 37167089256

E-mail: andra.ulme@rtu.lv

ORCID iD: https://orcid.org/0000-0001-9248-2032

\section{Anatoly Skopintsev}

Academy of Architecture and Arts of the Southern Federal University, Rostov-on-Don, 39 Budennovsky Str., 344002 Russia

Phone: + 79281123993

E-mail: scoparh@yandex.ru 